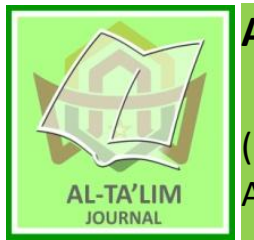

AL-TA'LIM JOURNAL, 25 (1), 2018, (1-12)

(Print ISSN 1410-7546 Online ISSN 2355-7893)

Available online at http://journal.tarbiyahiainib.ac.id/index.php/attalim

\title{
Summarising an Explanation Text with a Visual Representation as the Guidelines: How Does this Work to Represent Meaning?
}

\author{
Received: $21^{\text {th }}$ January 2018; Revised:13 ${ }^{\text {th }}$ February 2018; Accepted: $28^{\text {th }}$ February 2018 \\ Permalink/DOI: http://dx.doi.org/10.15548/jt.v25i1.379
}

\section{Mutuota Kigotho \\ University of New England, Australia. \\ E-mail: mkigotho@une.edu.au}

\section{Siti Sarah Fitriani*}

Universitas Syiah Kuala, Banda Aceh, Indonesia.

E-mail: ssfitriani@unsyiah.ac.id

*) Corresponding Author

\begin{abstract}
Metacognition has been popular in reading area, especially when it is related to comprehension and the representation of meanings. Combining metacognitive strategies to represent meanings from a text has been done by previous scholars to help readers construct meaning. In this paper, we present students' drawings and writings as the results of successive visualisation and summarisation activities in the classroom. We intended to find out the extent to which students' visual representations can be the guideline for them to write summaries. By employing qualitative research method, we collected visual representations and summaries from 26 undergraduate students studying at the English Education Department of Syiah Kuala University. To understand students' drawings, we consulted some literature on visual literacy and multimodality; while for the analysis of students' writings, we reviewed some literature on functional model to language. Based on the analysis, a productive visual representation leads to a strong summary, and vice versa. This result is further discussed in this paper.
\end{abstract}

Keywords: Visualisation; summarisation; representation of meaning

How to cite: Kigotho, M., \& Fitriani, S. (2018). Summarising an explanation text with a visual representation as the guidelines: How does this work to represent meaning?. Al-Ta Lim Journal, 25(1). doi: http://dx.doi.org/10.15548/jt.v25i1.379

\section{INTRODUCTION}

Summarising is one of the metacognitive strategies in reciprocal teaching that are aimed at increasing reading comprehension (Ahmadi \& Gilakjani, 2012; Al Azmi, 2012; Corte, Verschaffel, \& Ven, 2001; Duke \& Pearson, 2009a). Students practice to summarise texts improve their reading comprehension because they concentrate more on the text and theimportant information (Duke \& Pearson, 2009b; McNamara, 2012). Summarising is an activity that empowers readers to separate unimportant and important information (Day, 2004; Dole, Duffy, Roehler, \& Pearson, 1991; Harida, 2014; Kustati, 2017). Writing a summary gives an opportunity for students to paraphrase texts without changing the author's viewpoint but using their own language (Bailey, 2014; Klingner, Vaughn, \& Boardman, 2015; Mokhtari \& Reichard, 2002; Wallace, Pearman, Hail, \& Hurst, 2007) in a form of "coherent entity" (Pecjak, Podlesek, $\&$ Pirc, 2011). Producing summary that relates the key steps in an explanation or key events in a narrative pushes students to extract information and make this salient for readers. 
A summary is also a coherent entity too which is modelled (in a parallel way to a visualisation) on the source text. If it is genresensitive, the summary gives students powerful support for metacognition and hence comprehension.

Visualising is also included in metacognition (Ellis, Bond, \& Denton, 2012; Goh, 1997; Leopold \& Leutner, 2015; Sitindaon, Wijaya, \& Salam, 2013). Visualisation metacognitive strategy helps readers to construct meaning from a reading text so they understand the meaning. There are two types of visualisation; these are internal and external visualisations (Cohen \& Hegarty, 2007). Internal visualisation is the visual imagery created in readers' mind when they are reading (Hobbs, 2001; Trafton, Marshall, Mintz, \& Trickett, 2002; Trafton, Trickett, \& Mintz, 2005). External visualisation is a visual representations drawn by readers to represent the meaning in a text (Cohen \& Hegarty, 2007). The one used for this study is the external one.

For the students in this research, learning to write summaries gave them an opportunity to practice paraphrasing source texts using their own language following the genre stages of each source text. This activity, following visualisation, supported them in identifying important information, as well as in arranging the information systematically in the written mode. In this way, they were able to do in one mode (written mode) what they had rehearsed in another (e.g. visual mode). The success of the summarising done by the students depended on the success of their visualisation. It is therefore important to understand and then build on the relationship between students' visual representations and their summaries in fostering metacognition. Therefore, we posed this question to our research: "To what extent a visual representation can be a guideline to represent meaning in a summary?

The use of visualisation followed by summarisation is purposeful. Wepredicted that productive visual representations will lead to strong and coherent summaries. Those that make use of genre structure and apply relevant topic knowledge to their reading would produce a more effective summary. On similar grounds, it was predicted that a weak visual representation would lead to a less coherent summary. Where students fail to take account of genre stages or field knowledge, they will produce a less effective summary. To explore this in the current paper, it is necessary to firstly discuss and relate the characteristics of productive visual representations and summaries produced by students based on analytical parameters drawn from the functional model of language. We assume here, based on the literature (Callow \& Callow, 2013; Chan, 2011; Chan \& Unsworth, 2011; Daly \& Unsworth, 2011; Joyce \& Gaudin, 2007; Kress \& Van Leeuwen, 2006; McCloud, 2004; Unsworth, 2001; Unsworth \& Chan, 2009), that a productive visual representation based on the analytical parameter can be categorised in terms of four features: visualisation strategy, quality of image features, language features and relationship between image and language. The visualisation strategy students choose impacts on the formation of their visual representations. A good formation of a visual representation usually follows the stages of a text genre. Moreover, the language features and relationship between the language and the images have also impacted on the development of information presented in their visual representation. These two features can be considered good if they are able to communicate meaning based on the meaning written in a text. When we relate these characteristics of a visual representation to a summary, we assume that the productive characteristics of visual representations are also suggested to be found in strong summaries. In other words, if students produced a productive visual representation, they are predicted to also produce a strong and coherent summary.

Similarly to a productive drawing, a coherent summay also has some characteristics that we conclude here based on the literature on functional grammar (Droga \& Humphrey, 2003; Humphrey, Droga, \& Feez, 2012; Humphrey et al., 2012; MackenHorarik, 2002; Rose \& Martin, 2012). The 
features include genre stages, textual organisation (mode), and field knowledge. A strong summary uses well-formed genre stages within which students are able to develop a sequential order of appropriate information. The textual organisation of a paragraph is influenced by the mode in which it is produced. Within this feature, there are three aspects investigated in students' summaries in this study: sequencing, participant identification, and signposting. In addition to the use of genre and text organising features relevant to the written mode, students used what they knew of the subject matter or topic explored in each text. In the functional model of language, understanding of a topic is typically related to the field of discourse. If a student is familiar with the field (or topic) of a text, they are more likely to bring relevant knowledge to their reading of the text. Although this is not a major aspect of the current study, it is important to include it as relevant to students' metacognitive reading strategies. This is the last aspect investigated in students' summaries. In this study, aspects of processes, message development and vocabulary are included.

\section{METHOD}

This is a qualitative study analysing the relations between students' visual representations and how their drawings help them in summarising activity. We investigated the extent to which a visual representation is helpful enough to write a summary of an explanation text. To find out this matter, we collected data by using documentation technique which is by collecting students' visual representations and summaries of an explanation texts entitled 'The Arctic Haze'. The students participated in our research are the undergraduate students studying at the English Education Department of Syiah Kuala University, Banda Aceh, Indonesia. They were chosen purposely with the following criteria: have passed Reading 3 unit and agree to involve in this research voluntarily. The total number of students involved is 26. These students joined an intervention class and were taught to do successive visualisation and summarisation in reading process. In this paper, we do not focus on the intervention process; rather, we focus on the analysis of the students' products: the drawings and writings. Nevertheless, we briefly provide the activities in the intervention class.

The activities in the intervention classes were successive, with students producing visual representations before they wrote summaries of the source texts. The summaries written by students were based on the prior production of visual representations. It is important to note that students did not use the original source text when summarising it. Students created internal mental images and then externalised these through visual representations. In their visual representations, students drew some information - whether in detail or not - that they have read from source text. The detailed information they drew depended on their comprehension of the source text. When students had an active understanding of the source text, they tended to draw more detail and their visual representations could be considered to be productive works. This also means that students could comprehend the source text well. These productive drawings were used by students to write summaries after they had finished drawing their visual representations. These productive drawings also helped in their writing of the summaries, because they contributed an essential basis for summarising (Afflerbach, Pearson, \& Paris, 2008; Leopold \& Leutner, 2015; Meyer, Young, \& Bartlett, 2014; VanHoorn, Nourot, Scales, \& Alward, 2014; Woolley, 2010).

As mentioned previously, the textgiven to the students is an explanation text. The explanation text has two stages: General Statement and Explanation Sequence. Students were expected to write the summary within these two stages. Based on the analytical framework for analysing students' summaries, the characteristics of a strong summary are different from one genre to the other. For this explanation text, it is predicted 
that a strong explanation summary has the following features:

1. it is developed within well-formed stages of the genre.

2. It involves the use of logical and coherent sequencing. The sequence of the phenomena of haze formation based on the source text is listed below:

a. The Arctic haze particles appear to be similar to smog particles in industrial areas.

b. The Arctic haze consists of sulfates mixed with particles of carbon.

c. Particles of sulfates and carbon are formed when gaseous sulfur dioxide produced by burning sulfur-bearing coal is irradiated by sunlight and oxidized to sulfate, a process catalyzed by trace elements in the air.

d. Pure sulfate particles (droplets of sulfuric acid) which are colorless quickly capture the carbon particles. The mixture of these two particles causes darkness.

3. It keeps track of participants through appropriate pronoun references

4. The ordering of processes is fieldappropriate

5. Phenomena are explained using passive voice

6. Phenomena are ongoing and the text is written in the present tense.

7. The use of Expansion is strong, with links between messages either temporal, causal or conditional.
8. Concepts used are mostly classified as technical vocabulary.

The above characteristics suggest of a strong summary of an explanation text written by students. However, these strong features do not always exist in each of the students' summaries. We have an assumption that the features depend on their visual representations.

\section{RESULTS AND DISCUSSIONS}

In this paper, the result and discussion of the analysis are presented per student starting from Dina, then Jupe and Nani (all pseudonyms). These three out of 26 students were chosen because the characteristics of their viusal representations are different and this has affected the quality of their summary writings.

\section{Dina}

Dina's visual representation of the explanation text (as seen in Image 1 below) was considered productive, having strong characteristics based on the analytical framework. It will be considered here whether her productive visual representation helped her in writing a strong summary of the explanation text. Dina's summary consists of two parts: General Statement and Explanation Sequence.

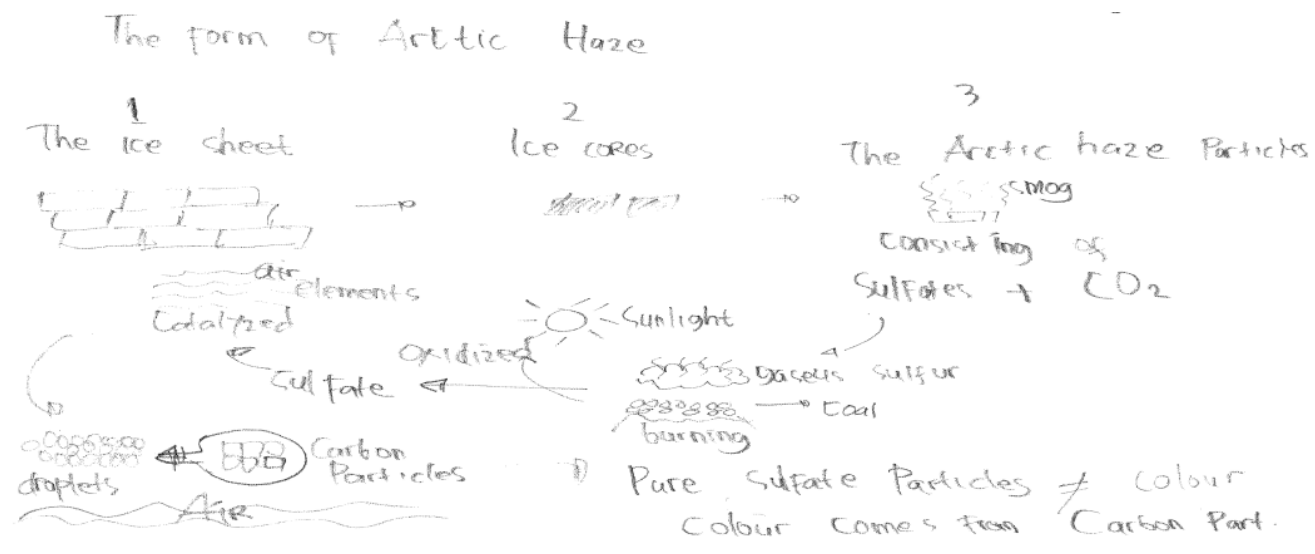

Figure 1. Dina’s Visual Representation 
Dina developed her summary (see Image 2 below) within well-formed genre stages. Information of the location of the Arctic haze and the similarity of haze and smog particles are appropriate for the general stage of her summary. In addition, in the explanation stage, Dina wrote the steps of haze formation sequentially. The development of information in both stages is well formed.

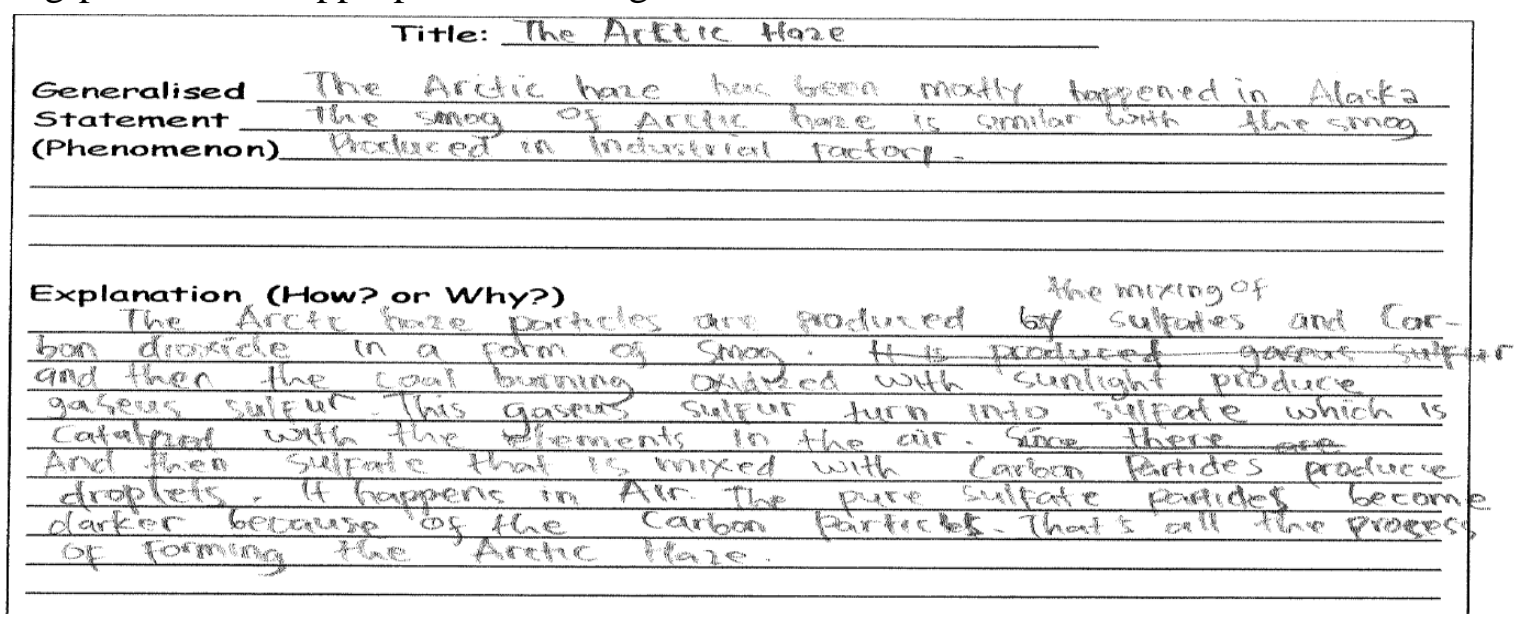

Figure 2. Dina's Summary

The sequencing appearing in Dina's summary can be considered to be logical and field appropriate. Dina explained the first process without using a connective; however, she used conjunctions like 'and then' in sentences 2 and 4, and 'because' in sentence 6 in the second part of the summary to connect the processes temporally and causally. She concluded her summary in the last sentence starting with a text reference, 'that is' to incorporate all the processes she wrote about in explaining the phenomena of haze formation. In terms of sequencing, Dina guides readers to follow the processes of haze formation logically.

Dina also kept track of the participants through appropriate referencing. For example in the second stage of her summary, Dina refered to things through demonstratives such as 'this' or 'that' in sentences 4 and 7 , and the impersonal pronoun 'it' in sentence 5. The use of the referents can be easily traced to the participants they refer to. It is possible to follow her account more easily as a consequence.

The ordering of processes in Dina's summary is field appropriate. Dina ordered the processes of haze formation sequentially, without missing any of these. In other words, she has recreated a complete account of the process of haze formation from first to last.

Dina's voice in her summary is mostly in passive form, which is appropriate for an explanation focusing on how haze particles are formed. For example, she wrote 'The Arctic haze particles are produced by the mixing of sulfates and carbon dioxide in a form of smog' in passive voice, making haze particles the subject and the end result of prior developments. Overall processes are written in passive voice. Furthermore, her use of present tense is field appropriate because phenomena like haze formation are ongoing. The universal present tense is typical of scientific genres like this. The characteristics of the processes are considered field appropriate.

Expansions also appear in Dina's summary. She expanded some information through enhancing and elaborating on the processes of haze formation, thus including more detailed information about the processes. Because an Explanation is used to explain how or why something happens, logical links stressing causes of events are often found. For example, Dina used Enhancement to give details about why sulfate particles become darker: 'The pure 
sulfate particles become darker $\|$ because of the carbon particles\|'. The use of Enhancement to present cause-effect conditions is evidence of a good understanding of the links between one process (e.g. darkening of carbon particles) and another (e.g. presence of carbon particles). Dina also used Elaboration in 'This gaseous sulfur turns into sulfate [[which is catalyzed with the elements in the air]]'. This allowed her to give a detailed description of what happens to the sulfate. The Expansions were used to support the summary to develop the information in a meaningful way.

Dina's summary also contains technical vocabulary used in the explanation text. For example she included terms like 'sulfate', 'carbon dioxide', 'coal', 'gaseous sulfur', 'oxidized', and 'droplets', but did so in an accurate way too. These terms are appropriate and helped her to explain the processes clearly and scientifically.

Based on the analysis using the above analytical framework, it can be said that Dina's summary is strong and coherent and
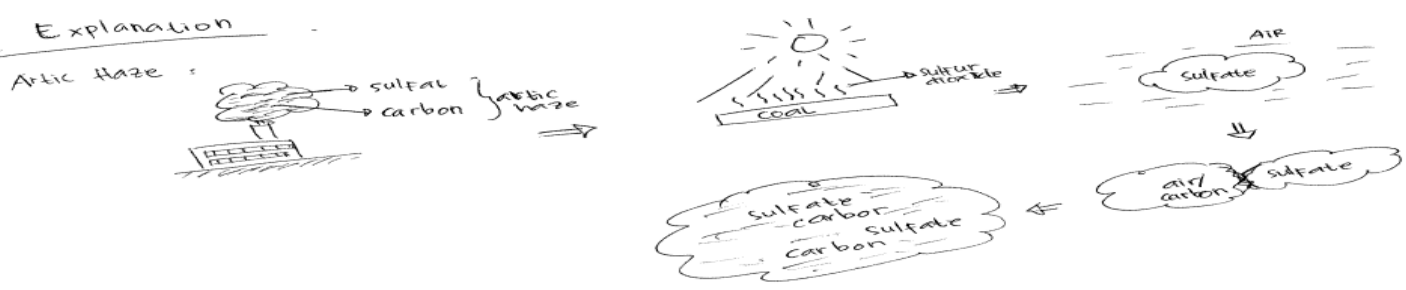

Figure 3. Jupe's Visual Representation

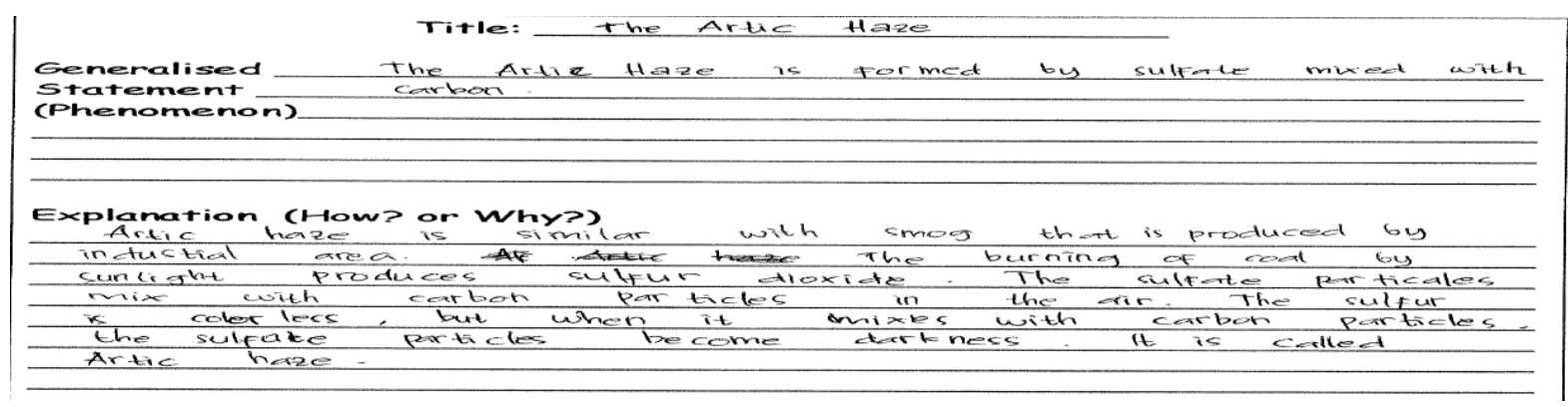

Figure 4. Jupe's Summary

Jupe wrote her summary within two stages, following the outline provided to her. In the first stage Jupe wrote, 'The Arctic haze is formed by sulphate mixed with carbon'. Here she tried to introduce the materials forming the Arctic haze has the following characteristics: it is generically well formed, it uses logical and coherent sequencing, it introduces and keeps track of participants through appropriate referencing, and it adopts field-appropriate processes, passive voice, and present tense. In addition, it includes strong Expansions of relevant points and uses technical terms effectively. Dina's productive visual representation of the explanation text appears to have supported her ability to write a strong explanation summary.

While Dina is relatively successful in her summarising of key information in the target text, other students found the task far more difficult. In the next section, the analysis continous by looking closely at Jupe's summary of the explanation text.

\section{Jupe}

Based on the analytical framework, Jupe's production of the visual representation of the explanation text was not as productive as to Dina's visualisation (see Image 3 below), due primarily to one misinterpretation of the processes of haze formation.

\section{年}


the phenomena in her summary shows one incomplete phenomenon of the processes. The incomplete one is seen when she wrote 'the burning of coal by sunlight produces sulphur dioxide'. It is expected that she continued with 'Gaseous sulphur dioxide is then irradiated by sunlight and oxidized to sulphate'. This process is the one that is missing in her summary. With one incomplete phenomenon, the genre stages of her summary cannot be considered as being well formed.

Text connectives were not involved in Jupe's summary,thus, the aspect of sequencing using text connectives cannot be assessed. The source text keeps using real terms for the materials involved in the phenomena of haze formation without using any specific reference. Jupe, however, includes three references to refer to three different participants. The first one is the relative pronoun 'that', which was written to refer to 'smog', in 'Arctic haze is similar to smog that is produced by industrial area'. She also wrote two subject pronouns 'it' to refer to two participants: 'sulfur' in 'The sulfur is colorless, but when it mixes....', and 'darkness of sulfate' in '......the sulfate particles become darkness. It is called the Arctic haze'. The use of references can be indicated as tracking participants because they are easy to be traced.

Because of one incomplete phenomenon of haze formation, the ordering of processes in Jupe's summary cannot be considered as fully field appropriate processing. This is similar to one incomplete process she drew in her visual representation. This means that Jupe is not able to present the complete processes of haze formation in her summary, which impacts on the understanding of the flow of processes.

The use of voice in her summary can be considered to be field-appropriate voice because she includes the use of passive voicefor example, 'is formed', 'is produced', and 'is called', to explain the phenomena of haze formation. This passive voice allowed her to make the participant affected the Theme of the sentence. However, her failure to sequence processes correctly and to relate these logically does indicate problems for Jupe with comprehension. In addition, Jupe developed her summary with the application of present tense, following the tense in the explanation text, which is considered field appropriate.

The use of Expansion in Jupe's summary can be considered strong. However, it is not as strong as the Expansion used in Dina's summary. Two Expansions, one as Elaboration and the other one as Enhancement, were used in the second stage of Jupe's summary. The Elaboration appears in 'Arctic haze is similar with smog [[that is produced by industrial areas]]'. This was used to describe 'smog' preceding it. The Enhancement is 'The sulfur is colorless, but when it mixes with carbon particles, the sulfate particles become darker'. This enabled Jupe to insert a condition influencing the darkening of the sulfate particles (the circumstances in which it happens). This kind of Expansion indicates that Jupe has understood at least one of the factors influencing the creation of sulfate particles in the explanation of ArcticHaze.

The vocabulary used in Jupe's summary can be considered technical, following the vocabulary in the explanation text. However, she did not include all important technical vocabulary in her summary to recreate the processes. Whilst she includes technical terms such as 'sulfate', 'carbon particles', 'coal', and 'sulfur dioxide', she does not include technical processes such as 'irradiate', 'oxidize', 'catalyze', and 'capture', which are associated with these nouns.

Based on the above analysis, it can be concluded that Jupe's summary is less effective than that of Dina for the 
following reasons. Firstly, one incomplete process of haze formation has impacted on the ordering of processes and, as a consequence, the sequence of processes does not match the explanation text sequencing. Secondly, although she used appropriate technical terms to represent key participants in the explanation sequence, she did not relate these to technical processes that represent the scientific processes occurring at each step. Similarly, her visual representation of the sequence of information does not match the target text's sequencing. Technical processes are also missing here too. Hence both metacognitive tasks are related and provide evidence of partial comprehension of the target text.
Jupe's work represents a mid-range achievement in her class. Some students like Nani struggled to manage the task at all,and it can be seen how she struggled with understanding the explanation text.

\section{Nani}

Nani's visual representation of the explanation text (as presented by Image 5 below) was presented and considered to be a weak production, especially in the Explanation Sequence part of the task. It was predicted that this would impact on her ability to develop the processes of haze formation in her summary.

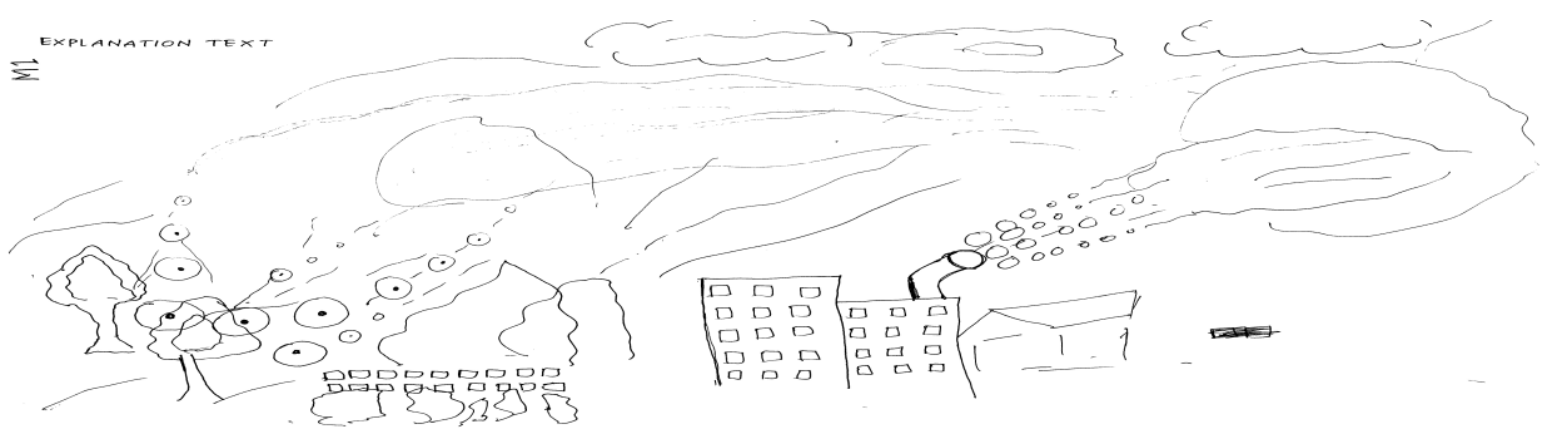

Figure 5. Nani's Visual Representation

This prediction is investigated in the following analysis and discussion of Nani's summary.

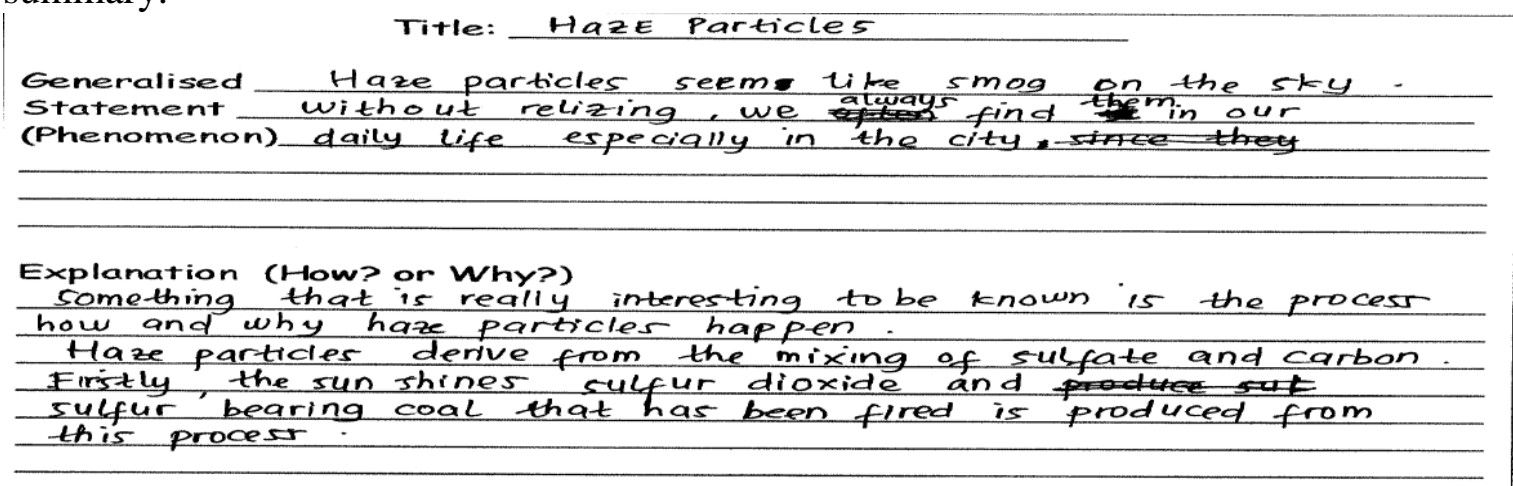

Figure 6. Nani's Summary

Nani used an engaging tenor in her opening sentences and the Generalized Statement is a reader-friendly piece of writing that introduces the origin of haze particles. However, the genre stages can be considered to be partially formed. Nani has actually developed her summary within two stages. The first stage was written well providing general information about Arctic haze. In the second stage, however, she was not able to complete her explanation of the processes of haze formation. The 
sequence of events in the formation of arctic haze stops at the first process and so the text is partially formed.

Because her text is incomplete, Nani's use of text connectives is also sparse. She used only one text connective, 'firstly', in the second part of her summary to present the first process of haze formation. This text connective is relevant to the first process. However, this is not followed by other connectives, such as 'second', 'next', or 'then', to continue to sequence the processes in the unfolding phenomenon of haze formation. The processes suddenly stop after the first process.

The referents in Nani's summary work best in the early section of the summary. For example, she used 'we' to refer to herself and the readers of her summary. The second example is the use of 'them', referring to the haze particles. The reference stops because the account stops, so participant identification is limited as a result.

The ordering of processes is indicated to be close to field-inappropriate processing. Nani was only able to record one correct process within haze formation. The rest of her explanation is irrelevant to the processes found in the explanation text. Furthermore, although there is one sentence using a passive construction ('that has been fired'), a few were written in active voice (e.g. 'We always find them in our daily life'). Nani did, however, use present tense verbs to communicate the ongoing nature of this physical phenomenon. This tense is relevant to the explanation genre. So, the use of tense is identified to be field appropriate.

Nani's use of Expansion is considered weak, because logical links between clauses do not help to build understanding of the processes she recreates in her summary. She used Elaboration to qualify the noun 'something'- 'something [[that is really interesting to be known]]' - but this is not field specific. Another example is 'and sulfur bearing coal [[that has been fired]] is produced from this process' which is more successful because it qualifies the origin of sulfur bearing coal. But, generally, Nani did not deploy the resources of enhancement, which would have enabled her to explain the temporal or causal links between one process and another.

Nani's vocabulary includes a mix of semi-technical and technical terms. She was able to include technical terms such as 'sulfate', 'carbon', 'sulfur dioxide', and 'sulfur bearing coal', but she did not include technical processes. Instead, Nani used simple verbs to explain the processes, such as 'shines' instead of 'irradiates', and 'sulfur bearing coal that has been fired' instead of 'burning sulfur bearing coal'.

From the overall analysis, Nani's summary can be considered weak for the following reasons. Firstly, it is partially formed as a genre with an engaging opening paragraph but a limited explanation sequence. Secondly, the ordering of processes is field in appropriate, containing only one phase of the sequence. The voice in her account would be stronger if she had understood and recreated the whole of the sequence of physical events. Finally, her use of expansion does not help her to develop meaningful processes of haze formation, featuring primarily Elaboration rather than Enhancement or Extension. Similarly, her visual representation presented the process not in sequential order, but in a synoptic figure. She drew her representation in the form of scenery or artwork, which does not present clear processes of haze formation. It is also not relevant to the explanation text. The characteristics of her visual representation did not support her in writing the summary. It can be surmised 
that a weak visual representation has led to a weak summary.

The overall analysis of students' summaries of the explanation text has shown a relationship between the performance of students visual representations and students' summaries. Dina, for example, was able to draw a productive visual representation that accurately represented the complete processes mentioned in the explanation text with the use of images and language. This visual representation helped her in writing the summary of the explanation text, including complete processes which are ordered sequentially using appropriate grammatical structure relevant to the explanation text. In contrast, Jupe and Nani wrote less effective summaries because their visual representations did not provide enough information about the phenomena of haze formation. Besides this factor, there are some other possible factors for students' success in drawing and writing of the text that can be taken into consideration in the case of the students: familiarity with the explanation genre, understanding of the text, and grammatical knowledge in writing a coherent text.

\section{CONCLUSION RECOMMENDATION}

AND

Based on the analysis, succesive visualisation and summarisation metacognitive strategies can be used by students in reading process to represent meanings that they already understood from a reading passage if only they can do both the strategies appropriately. Because students summarised a text based on their visual representations, they need to do visualisation properly to be able to represent the correct information in their drawing based on the information found in the text. By doing so, they can also write a strong summary.

\section{REFERENCES}

Afflerbach, P., Pearson, P. D., \& Paris, S. G. (2008). Clarifying differences between reading skills and reading strategies. The Reading Teacher, 61(5), 364-373.

Ahmadi, M. R., \& Gilakjani, A. P. (2012). Reciprocal teaching strategies and their impacts on English reading comprehension. Theory and Practice in Language Studies, 2(10), 2053.

Al Azmi, H. (2012). The students' language learning strategies in reading and speaking. Al-Ta'lim Journal, 19 (2), 122-133.

Bailey, S. (2014). Academic writing: A handbook for international students. Routledge.

Callow, J., \& Callow, J. (2013). The shape of text to come. Primary English Teaching Association Australia (PETAA).

Chan, E. (2011). Integrating visual and verbal meaning in multimodal text comprehension: Towards a model of intermodal relations. Semiotic Margins. Meanings in Multimodalities, 144-167.

Chan, E., \& Unsworth, L. (2011). Imagelanguage interaction in online reading environments: challenges for students' reading comprehension. The Australian Educational Researcher, 38(2), 181.

Cohen, C. A., \& Hegarty, M. (2007). Individual differences in use of external visualisations to perform an internal visualisation task. Applied Cognitive Psychology, 21(6), 701-711. 
Corte, E., Verschaffel, L., \& Ven, A. (2001). Improving text comprehension strategies in upper primary school children: A design experiment. British Journal of Educational Psychology, 71(4), 531-559.

Daly, A., \& Unsworth, L. (2011). Analysis and comprehension of multimodal texts. Australian Journal of Language and Literacy, The, 34(1), 61.

Day, R. R. (2004). Extensive reading activities for teaching language. Ernst Klett Sprachen.

Dole, J. A., Duffy, G. G., Roehler, L. R., \& Pearson, P. D. (1991). Moving from the old to the new: Research on reading comprehension instruction. Review of Educational Research, 61(2), 239-264.

Droga, L., \& Humphrey, S. (2003). Grammar and meaning: An introduction for primary teachers. Target Texts New South Wales, Australia.

Duke, N. K., \& Pearson, P. D. (2009a). Effective practices for developing reading comprehension. Journal of Education, 189(1-2), 107-122.

Duke, N. K., \& Pearson, P. D. (2009b). Effective practices for developing reading comprehension. Journal of Education, 189(1-2), 107-122.

Ellis, A. K., Bond, J. B., \& Denton, D. W. (2012). An analytical literature review of the effects of metacognitive teaching strategies in primary and secondary student populations. Asia Pacific Journal of Educational Development (APJED), 1(1), 9-23.
Goh, C. (1997). Metacognitive awareness and second language listeners. ELT Journal, 51(4), 361-369.

Harida, E. S. (2014). Students' Ability and Difficulties in Understanding English Text (A Study at English Program IAIN Padangsidimpuan). Al-Ta Lim Journal, 21(3), 183188.

Hobbs, R. (2001). Improving reading comprehension by using media literacy activities. Voices from the Middle, 8(4), 44.

Humphrey, S., Droga, L., \& Feez, S. (2012). Grammar and meaning. Primary English Teaching Association Australia (PETAA).

Joyce, H. D. S., \& Gaudin, J. (2007). Interpreting the visual: A resource book for teachers. Phoenix Education.

Klingner, J. K., Vaughn, S., \& Boardman, A. (2015). Teaching reading comprehension to students with learning difficulties, 2/E. Guilford Publications.

Kress, G., \& Van Leeuwen, T. (2006). Reading images: The grammar of visual images. Oxon: Routledge.

Kustati, M. (2017). Enhancing Islamic Students' Reading Comprehension through Predict Organize Search Summarize Evaluate Strategy. AlTa 'lim Journal, 24(1), 1-8.

Leopold, C., \& Leutner, D. (2015). Improving students' science text comprehension through metacognitive self-regulation when applying learning strategies. Metacognition and Learning, 10(3), 313-346.

Macken-Horarik, M. (2002). Something to shoot for": A systemic functional 
approach to teaching genre in secondary school science. Genre in the Classroom: Multiple Perspectives, 17-42.

McCloud, S. (2004). The vocabulary of comics. Visual Rhetoric in a Digital World, 195-208.

McNamara, D. S. (2012). Reading comprehension strategies: Theories, interventions, and technologies. Psychology Press.

Meyer, B. J., Young, C. J., \& Bartlett, B. J. (2014). Memory improved: Reading and memory enhancement across the life span through strategic text structures. Psychology Press.

Mokhtari, K., \& Reichard, C. A. (2002). Assessing students' metacognitive awareness of reading strategies. Journal of Educational Psychology, 94(2), 249.

Pecjak, S., Podlesek, A., \& Pirc, T. (2011). Model of reading comprehension for 5th grade students. Studia Psychologica, 53(1), 53.

Rose, D., \& Martin, J. R. (2012). Learning to write, reading to learn: Genre, knowledge and pedagogy in the Sydney School. Equinox Sheffield.

Sitindaon, M., Wijaya, B., \& Salam, U. (2013). Metacognitive Online Reading Strategy Practiced By English Students. Jurnal Pendidikan Dan Pembelajaran, 2(11).
Trafton, J. G., Marshall, S., Mintz, F., \& Trickett, S. B. (2002). Extracting explicit and implict information from complex visualizations. In International Conference on Theory and Application of Diagrams (pp. 206-220). Springer.

Trafton, J. G., Trickett, S. B., \& Mintz, F. E. (2005). Connecting internal and external representations: Spatial transformations of scientific visualizations. Foundations of Science, 10(1), 89-106.

Unsworth, L. (2001). Teaching multiliteracies across the curriculum. BuckinghamPhiladelphia: Open University Press. Retrieved September, 26, 2005.

Unsworth, L., \& Chan, E. (2009). Bridging multimodal literacies and national assessment programs in literacy. Australian Journal of Language and Literacy, The, 32(3), 245.

VanHoorn, J., Nourot, P. M., Scales, B., \& Alward, K. R. (2014). Play at the center of the curriculum. Pearson Higher Ed.

Wallace, R., Pearman, C., Hail, C., \& Hurst, B. (2007). Writing for comprehension. Reading Horizons, $48(1), 5$.

Woolley, G. (2010). Developing reading comprehension: combining visual and verbal cognitive processes. Australian Journal of Language and Literacy, The, 33(2), 108. 